\title{
Awareness of the 2010 Guidelines Implemented by the New York State Education Department for Respiratory Therapists in Their Role as Clinical Preceptors
}

\author{
Stephen G Smith MPA RRT, John Brittelli MSc RRT, and Lisa Benz Scott PhD
}

\begin{abstract}
BACKGROUND: In 1993, the New York State (NYS) legislature and governor signed into law the Respiratory Therapy Guide to Practice Education Law to guide and regulate the profession of respiratory care under the auspices of the New York State Education Department. New guidelines were implemented by the New York State Education Department for respiratory therapists (RTs) in 2010 to provide the opportunity for RTs to receive continuing education units (CEUs) when participating as clinical preceptors. This study was conducted in June 2012 to determine the extent to which the NYS RTs are aware of the new licensing guidelines and amendments. METHODS: In June 2012, a web-based survey was e-mailed to 2,503 NYS members of the New York State Society for Respiratory Care, 14\% of which $(n=360)$ completed the survey. The survey included 21 items to assess RTs' awareness of the licensing guidelines that were implemented in 2010, and these respondents were analyzed using basic descriptive statistics. RESULTS: The study showed that $50 \%$ of the respondents were not aware of eligibility to earn CEUs as a clinical preceptor in NYS. Twenty-eight percent responded correctly that licensed RTs were eligible to earn CEUs as a clinical preceptor in NYS. In addition, $67 \%$ of those who responded were unaware of how many CEUs could be earned for each renewal period for clinical precepting. Finally, $70 \%$ of the respondents indicated that they would be inclined to seek employment at a facility that has a clinical affiliation with a university or college respiratory care program. CONCLUSIONS: The findings indicate that more education is needed in NYS to make licensed RTs aware of the 2010 guidelines. Practitioners may require incentives to become actively involved in the clinical education of respiratory care students as their clinical preceptors. Key words: clinical preceptor; continuing education units; respiratory therapists; respiratory therapy technicians; licensing guidelines. [Respir Care 2014;59(12):1846-1850.

(c) 2014 Daedalus Enterprises]
\end{abstract}

\section{Introduction}

In 1993, the New York State (NYS) legislators passed, and the governor signed into law, the Respiratory Therapy Guide to Practice (Education Law: Article 164), regulating the practice of respiratory therapy in NYS. The New York State Education Department, which oversees the practice of respiratory therapy, has a 2-tier system for licensing in

\footnotetext{
Mr Smith and Mr Brittelli are affiliated with the Respiratory Care Program, and Dr Scott is affiliated with the Program in Public Health, School of Health Technology and Management, Stony Brook University, Stony Brook, New York.

There is no conflict of interest or financial support involving the authors of this study.
}

New York. To become a licensed respiratory therapist (RT), it is required that the practitioner pass the National Board for Respiratory Care's certification and registered RT written and simulation exams. Once the exams have been successfully completed, the practitioner is eligible for an RT license in NYS. RTs and respiratory therapy technicians (RTTs) can act as clinical preceptors, but only RTs are eligible for continuing education units (CEUs) in NYS.

\footnotetext{
Correspondence: Stephen G Smith MPA RRT, Respiratory Care Program, School of Health Technology and Management, Stony Brook University, Stony Brook, NY 11794-8203. E-mail: stephen.smith@ stonybrook.edu.
}

DOI: $10.4187 /$ respcare. 03029 
During the last $20 \mathrm{y}$, there have been significant additions to the practice of respiratory therapy. As of January 1, 2003, legislation requires continuing education for all licensed RTs and licensed RTTs. As a condition of maintaining a license to practice respiratory therapy in NYS, the law states that at each triennial registration period, an applicant for licensure as an RT shall complete a minimum of $30 \mathrm{~h}$ of acceptable, formal, continuing education, provided that no more than $15 \mathrm{~h}$ of said continuing education shall consist of self-study courses, and RTTs shall complete a minimum of $24 \mathrm{~h}$ of acceptable formal continuing education and that no more than $12 \mathrm{~h}$ of such continuing education shall consist of self-study courses. In 2003, an amendment was added to the statute to indicate that RTs can accept written orders not only from a licensed physician but also from a certified nurse practitioner. ${ }^{1}$ In 2010 , the New York State Education Department added to their guidelines, and the opportunity now exists for RTs to receive 10 continuing educations units, within the 3 -y reregistration period, when participating as clinical preceptors in educating RT students in their clinical rotations.

Clinical education is a critical component of professional allied health education. Clinical education provides students with experiences in real-life situations involving actual patients, and it offers students the opportunity to apply theory to practice while fostering problem solving, decision making, and critical thinking. ${ }^{2}$ Clinical preceptors play a significant role in the ongoing education for respiratory therapy students in the clinical setting. Respiratory care programs depend on voluntary clinical preceptors to build the bridge that takes students from the classroom setting to the clinical setting. In NYS, clinical preceptors are members of the respiratory care staff at the clinical site where students are doing their clinical rotations. Historically, the clinical preceptors have not been financially compensated to participate in this role. Although it is possible that some schools do pay or compensate preceptors, there are no data available, and it is likely that the vast majority are not paid. As a result of the difficulty in recruiting preceptors, the New York State Respiratory Therapy Licensure Board decided that it would be advantageous to provide these practitioners an incentive to participate in this academic responsibility. The Board developed new CEU guidelines to help further the recruiting process and thought that an additional incentive of 10 CEUs would help recruit competent and dedicated practitioners to become involved in precepting respiratory care students. It is imperative for preceptors to remain engaged in the educational process for these students. In addition, it is important for students to be able to put to practice what they have learned in the didactic environment. To accomplish this goal, clinical preceptors are needed in sufficient numbers to provide the necessary skills and knowledge for

\section{QUICK LOOK}

\section{Current knowledge}

The New York State (NYS) legislature signed into law the Respiratory Therapy Guide to Practice Education Law to guide and regulate the profession of respiratory care. New guidelines were implemented for respiratory therapists (RTs) in 2010 to provide the opportunity for respiratory care practitioners to receive continuing education units (CEUs) when participating as clinical preceptors.

\section{What this paper contributes to our knowledge}

In a survey of NYS RTs with a $14 \%$ response rate, only $23 \%$ of clinical preceptors applied for CEUs, and only half knew who was eligible for the credits. Improved distribution of the guidelines and rules in NYS is warranted.

students to obtain a quality clinical educational experience.

In 2010, the New York State Education Department added to the guidelines the opportunity for RTs to receive 10 continuing education credits, within the 3-y re-registration period, when participating as clinical preceptors in educating RT students in their clinical rotations. The Respiratory Therapy Board unanimously agreed that this would encourage practicing RTs to become clinical preceptors. By providing this incentive for clinical preceptors, NYS is breaking new ground to encourage RTs to pursue a clinical preceptor role. This is crucial because clinical education, the integration of theoretic and practical educational components into real-life situations with patients, should promote and help ensure a positive and constructive learning experience so that appropriate skills, behaviors, and attitudes for future professional practice are learned and applied. ${ }^{3}$ The purpose of this study is to assess the extent to which practitioners are aware of and motivated by the New York State Education Department's new clinical guidelines.

\section{Methods}

The study was a cross-sectional self-report survey that was administered using an online program (surveymonkey.com) among a convenience sample of RTs and RTTs. Participants were recruited via an e-mailed invitation in collaboration with the New York State Society for Respiratory Care. Ethics approval for the study protocol was obtained from the Committee on Research Involving Human Subjects at Stony Brook University (Stony Brook, 
New York). The survey was developed by the authors based on their content expertise, and items were constructed by a behavioral scientist who has extensive knowledge and experience with survey research methods involving healthcare providers. An early draft of the survey tool was piloted by RTs and faculty members $(n=7)$ for face validity, logical flow, and overall clarity of expression for items, as well as the time required for completion. In June 2012, 2,503 members of the New York State Society for Respiratory Care were sent an e-mail inviting their participation in this study, which included a link to access a 21-item survey to assess RTs' and RTTs' awareness of the new education guidelines involving respiratory care preceptors in NYS. The survey included measures of the respondent's employment settings (community hospital, university hospital, tertiary care center or non-university hospital, home care, university or college, sleep disorder center, long-term or nursing home, physician's office, cardiac catheterization laboratory, and other), title, level of education completed, years of practice, type of license (RT, RTT, and other), knowledge of the New York State Education Department's new guideline regarding CEUs and preceptors, knowledge of earning CEUs to become a clinical preceptor, difficulty of recruiting RTs as clinical preceptors before and after implementation of the new guidelines, and interest in seeking employment at a facility that has a clinical affiliation with a university or college respiratory care program. One reminder was sent $14 \mathrm{~d}$ after the initial solicitation. The responses were analyzed in the aggregate using software provided by surveymonkey.com. Findings were summarized using basic descriptive statistics.

\section{Results}

\section{Participant Characteristics}

Position/Title of Respondents/Work Environment/Credentials. Of the 2,503 members invited to complete the survey, $360(14 \%)$ responded. The majority of the practitioners $(45 \%)$ who responded to the survey were practicing staff therapists. Table 1 shows the characteristics of the respondents. The respondents were asked to select all that apply. This question has a multiple-response option; therefore, the number of responses exceeds the total number of respondents in the sample.

The majority of respondents $(30 \%)$ indicated that their current work environment is a community hospital setting, followed by those respondents (17\%) who currently work in a university hospital setting. This question has a multiple-response option; therefore, the number of responses exceeds the total number of respondents in the sample.

The majority of respondents $(73 \%)$ were licensed RTs, and $24 \%$ were licensed RTTs. The remaining $3 \%$ did not currently hold an NYS license to practice and therefore
Table 1. Participant Characteristics

\begin{tabular}{|c|c|c|}
\hline & $n^{*}$ & Percentage \\
\hline \multicolumn{3}{|l|}{ Position/title } \\
\hline Staff therapist & 173 & 45 \\
\hline Director & 56 & 14 \\
\hline Supervisor & 42 & 11 \\
\hline Educator & 39 & 10 \\
\hline Assistant/associate director & 11 & 3 \\
\hline RT or RTT not currently employed & 10 & 3 \\
\hline Other & 57 & 14 \\
\hline \multicolumn{3}{|l|}{ Work Environment } \\
\hline Community hospital & 123 & 30 \\
\hline University hospital & 72 & 17 \\
\hline Tertiary care center/non-university hospital & 51 & 12 \\
\hline Home care & 37 & 9 \\
\hline University/college & 26 & 6 \\
\hline Sleep disorder center & 24 & 6 \\
\hline Long-term/nursing home & 23 & 6 \\
\hline Physician's office & 18 & 4 \\
\hline Cardiac catheterization laboratory & 3 & 1 \\
\hline Other & 39 & 9 \\
\hline \multicolumn{3}{|l|}{ Credentials } \\
\hline Licensed RT & 260 & 73 \\
\hline Licensed RTT & 85 & 24 \\
\hline Not applicable & 13 & 3 \\
\hline \multicolumn{3}{|l|}{$\begin{array}{l}\text { * Some questions may be answered more than once. } \\
\text { RT }=\text { respiratory therapist } \\
\text { RTT = respiratory therapy technician }\end{array}$} \\
\hline
\end{tabular}

were not included in the study. Of 360 respondents, 2 participants did not provide a response.

Years of Practice/Education of Respondents. The majority $(61 \%)$ of respondents indicated possessing 20-plus years of practice experience as an RT or RTT. In addition, $36 \%$ reported having an associate's degree, $41 \%$ reported having a bachelor's degree, and 19\% reported having a master's degree. Fifty-eight percent reported that their place of employment has an affiliation with a university or college respiratory care program.

Knowledge of CEU Requirement. Ninety-one percent of the respondents were aware that licensed RTs are required to obtain 30 CEUs for each renewal period. Only $36 \%$ of the respondents knew that 24 CEUs were required for each renewal period for licensed RTTs. However, a high percentage $(90 \%)$ knew that the renewal period was every $3 \mathrm{y}$.

Knowledge of CEU Credits for Clinical Preceptors. In response to the questions regarding CEUs that can be earned as a clinical preceptor, 50\% did not know who was eligible to earn these credits, $28 \%$ responded correctly that licensed RTs were eligible to earn CEUs as a clinical preceptor in 


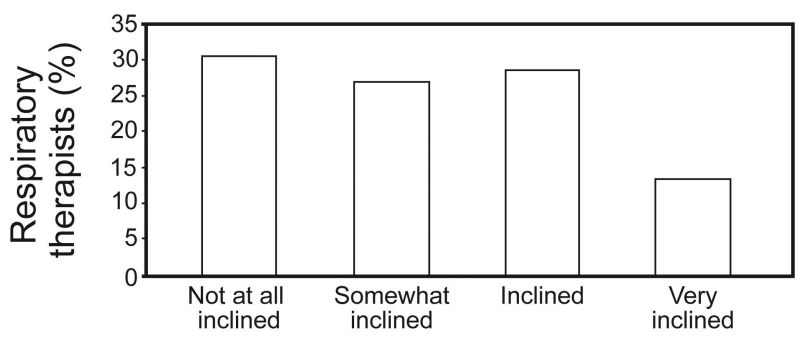

Fig. 1. Respiratory therapists were asked if they would be inclined to seek employment at an institution that has a clinical affiliation with a university/college respiratory care program.

NYS, and $67 \%$ did not know how many credits could be earned for each renewal period for clinical precepting. Seventy-seven percent of those surveyed were unaware of the year that these new guidelines were implemented. In addition, only $23 \%$ of clinical preceptors were actually applying for CEUs, $40 \%$ who practiced as clinical preceptors did not apply for CEUs, and 37\% did not know whether the clinical preceptors were applying for CEUs in their place of employment. Finally, only $20 \%$ knew that the Program Director of Clinical Education was the individual permitted to issue CEUs for clinical precepting in NYS.

Difficulty in Recruiting RTs as Clinical Preceptors. The survey included questions regarding experiences to recruit RTs to become clinical preceptors before and after the implementation of the new guidelines (before 2010 and after 2010). The following 2 questions were asked. (1) In the years before 2010, how difficult was it to recruit RTs as clinical preceptors? (2) In the years 2010-2011, after the implementation of the new guidelines, how difficult was it to recruit RTs as clinical preceptors? With regard to the first question, $58 \%$ indicated that it was difficult to recruit RTs as clinical preceptors in the years before 2010 . Likewise, $60 \%$ of respondents indicated that it was difficult to recruit RTs as clinical preceptors in reference to the years 2010-2011.

\section{Interest in Seeking Employment at a Facility That Has a Clinical Affiliation With a University or College Respiratory Care Program}

With the implementation of the new guidelines, $70 \%$ of the respondents stated that they would be "somewhat inclined," "inclined," or "very inclined" to seek employment at an institution that has a clinical affiliation with a university or college respiratory care program (Fig. 1).

\section{Discussion}

Clinical preceptors play a vital role in the clinical educational process of respiratory care students. The literature suggests that clinical preceptors are frequently expected to take the preceptorship role on in addition to their usual work load. ${ }^{4}$ Therefore, providing care to patients and at the same time instructing students can be challenging. Under many circumstances in NYS, clinical preceptors provide this important service voluntarily. The intention of implementing these new guidelines was to help retain and attract clinical preceptors who will act professionally, competently, and responsibly in preparing RT students for future practice. Along with these intentions, the recognition alone does not necessarily involve additional money, but acknowledgments such as letters of recognition, certificates, badges, and increased access to professional development or formal award functions have been found to increase satisfaction and commitment to the role as a clinical preceptor. ${ }^{4}$ It was believed that with the implementation of these guidelines, providing one third of the CEUs required with each renewal period would encourage therapists to become clinical preceptors. Thus, receiving these CEUs would be an incentive. The results of the study showed that this was not the case. Respondents indicated that in reference to years before the 2010 implementation of the guidelines, it was difficult to recruit RTs as clinical preceptors; after the 2010 implementation, there was little difference in recruitment ( $58 \%$ vs $60 \%$, respectively). As a result, the study indicates that there was a lack of knowledge or understanding of these new guidelines to obtain 10 CEUs to serve as a clinical preceptor, which suggests that further education is needed to advise RTs that they can receive CEUs as clinical preceptors.

We were encouraged to see that RTs $(70 \%)$ would be more inclined to seek employment in a health-care facility that had an affiliation with a university or college respiratory care program and receive CEUs for their clinical precepting.

A limitation of the study is that the survey was sent to a convenience sample of 2,503 practitioners in NYS who are members of the New York State Society for Respiratory Care, and the response rate of only $14 \%$ may not represent the experiences and opinions of members at large or nonmembers. It is possible that the respondents selfselected to participate and differed in some important ways from nonrespondents or from those who, for some reason, never learned of the opportunity to participate (perhaps due to an e-mail address error among members of the New York State Society for Respiratory Care). According to the New York State Education Department, there are 5,057 licensed RTs and 1,182 licensed RTTs eligible to practice in New York. ${ }^{5}$ Only $40 \%$ of the licensed practitioners in NYS are members of the American Association for Respiratory Care.

Although the response rate was low, it is plausible that respondents may be similar to nonrespondents. In a recent national study of RTs published in 2009 by the American 
Association for Respiratory Care known as the Human Resource Survey, the authors reported the characteristics of a national random sample of RTs. ${ }^{6}$ At the time of this study, there were 145,117 RTs in the United States, and $5 \%$ were sampled using random sampling methods. There were 3,139 therapists who submitted responses (representing only $2.2 \%$ of the total population). Among the respondents, $44 \%$ of practitioners had an associate's degree (vs $36 \%$ in our study), $33 \%$ had a bachelor's degree (vs $41 \%$ in our study), $13 \%$ held a master's degree (vs 19\% in our study), and only $1 \%$ held a doctorate level degree (both studies). Although the education level is only one characteristic, it is reasonable to say that our sample was similar to those who responded.

Despite these limitations, we believe that the results of the study can inform programs to better educate practitioners regarding their eligibility to receive CEUs for clinical precepting. Future studies should be done to determine whether these new guidelines have encouraged RTs to become clinical preceptors, and for future studies, we recommend soliciting the help of the New York State Education Department to reach a greater number of RTs.

\section{Conclusion}

The results of this study certainly indicate that the NYS respiratory care profession needs to do a better job of informing the professionals who are working as clinical preceptors that these new guidelines have been implemented. This information can be better communicated by the New York State Society for Respiratory Care by placing the guidelines on the web site, in addition to the link directing practitioners to the New York State Education Department's continuing education questions and answers.
Finally, professional societies, journals, and newsletters could include information and CEU opportunities at conferences and symposiums for RTs that would strengthen their knowledge of current policies and guidelines relevant to practice. Collaborating with university and college respiratory care programs will help clinical preceptors foster educational opportunities in the clinical setting that will facilitate the preparation of respiratory care students by improving integration of theory into practice and clinical decision-making skills. ${ }^{7}$ Providing CEUs for this important responsibility may help in recruiting and maintaining clinical preceptors. We would encourage other states and other professions to consider providing CEUs to aide in recruiting clinical preceptors.

\section{REFERENCES}

1. Respiratory Therapy Guide to Practice; Education Law: Article 164, Respiratory Therapists and Respiratory Therapy Technicians. New York State Education Department, Office of the Professions; 1993.

2. Lauber CA, Toth PE, Leary PA, Martin RD, Killian CB. Programs directors' and clinical instructors' perceptions for important clinicalinstructor behavior categories in the delivery of athletic training clinical instructions. J Athl Train 2003;38(4):336-341.

3. Laurent T, Weidnet TG. Clinical instructors and student athletic trainers perceptions of helpful clinical instructor characteristics. J Athl Train 2001;36(1):58-61.

4. Happell B. A model of preceptorship in nursing: reflecting the complex functions of the role. Nurs Educ Perspect 2009;30(6):372-376.

5. Office of the Professions. New York State Respiratory License Statistics. Updated February 5, 2014. www.op.nysed.gov/prof/rt/ rtcounts.htm. Accessed June 17, 2014.

6. American Association for Respiratory Care. AARC 2009 respiratory therapist human resource study. Irving, Texas: AARC; 2009.

7. Keshk LI, El Dahshan ME. Effect of work problems on clinical instructors performance in Faculty of Nursing, Menoufiya University. J Am Sci 2012;8(4):380-391. 